\title{
MUSCULUS STERNALIS IN FILIPINOS ${ }^{1}$
}

\author{
SABAS E. YAP \\ Department of Anatomy, College of Medicine and Surgery, University of the \\ Philippines \\ TWO plates (ten Figures)
}

The musculus sternalis is a small muscle of the thorax encountered in the dissection-room in no less than 3 per cent of all cases. For a long time it has aroused the interest of many anatomists because of the different possibilities of explaining its homologies. It was described for the first time in 1604 by Cabrolius (1), but its connections and relations were not precisely understood until 1723 , when Du Puy gave a clear account of the muscle. From that time on this muscle has been very extensively discussed, and in recent years its homology has taxed the ingenuity of many investigators, and various interesting hypotheses had been formulated in their attempts to explain it. Its varied nerve supply, connections, and relations which have been considered as important points in deciding its homology make of this muscle an interesting specimen to anatomists.

It has been found in both sexes in adult cadavers and in a surprisingly large proportion in anencephalous foetuses. It has been reported in different races. Its occurrence in Filipinos is the subject of this short paper.

The present work comprises an observation on 136 cadavers dissected in the Department of Anatomy for the last five years, and includes besides a special dissection made on ten anencephalous monsters (four males and six females) and ten apparently normal foetuses (five males and five females).

I was able to collect data of its presence in five out of the 136 adult cadavers, or a proportion of about 3.6 per cent, and found it present in four anencephalous monsters of the ten examined (40 per cent) and in two of the normal foetuses ( 20 per cent).

1 Read before the Manila Medical Society, October. 4, 1920. 
Two of the five adult cadavers showing the muscle were males, and in each one it was present on only one side; the remaining three were females, and in each the muscle was bilateral. We also found the muscle bilateral in the four monsters which were all females and in one male and one female normal foetus. We therefore had a total of twenty specimens. Attention is invited to the fact that most of our dissected adult cadavers were males.

The following are the cases observed:

Case I. Male, 36 years old, prisoner. Musculus sternalis, unilateral, left side. It measured $2 \mathrm{~cm}$. at its widest part and about $10 \mathrm{~cm}$. in length. It originated by a flattened tendinous band from the pars abdominalis of the left pectoralis major at the level of the sixth rib about $3.75 \mathrm{~cm}$. from the center of the ziphoid process of the sternum.

Its fibers ran upward and medially and gained attachment by a small tendon to the second costal cartilage, blending there with the sternal origins of the pectoralis major and the sternocleido mastoids from the manubrium sterni. The nerve supply was furnished by fibers from the medial anterior thoracic which penetrated the deep surface of the muscle near its medial margin.

Case II. Female, 85 years of age, musculus sternalis, bilateral. Both muscles were about the same in length and width, $10 \mathrm{~cm}$. long and $2.5 \mathrm{~cm}$. wide. Each originated from the pectoralis major at the level of the fourth rib, the fibers ran upward and medially and were inserted to the anterior surface of the sternoclavicular joint, blending with the sternal origin of the corresponding sternocleido mastoid muscle. The nerve supply was also from the anterior thoracic nerves.

Case III. Female, insane, 89 years old, musculus sternalis, bilateral. The left muscle was shorter and much smaller than the right. It originated by a tendinous band from the left rectus sheath and the sixth rib, the fibers ran upward and medially to be inserted by tendinous band into the manubrium sterni at the level of the second rib. A tendinous slip separated from this tendon of insertion and crossed medially to unite with the tendon of the right musculus sternalis. The nerve supply was from the anterior thoracic.

The right muscle originated also from the right rectus sheath and sixth rib by a tendinous band, and ran upward and medially to gain insertion in common with the sternal origins of the two sternocleido mastoid muscles. The nerve supply was identical to that of the left muscle.

Case IV. Female, insane, 78 years old, musculus sternalis, bilateral. Both muscles were of about the same size (fleshy portions about $4 \mathrm{~cm}$. long and $1.5 \mathrm{~mm}$. wide) each originating by a long tendinous slip from the fifth costal cartilage and by radiating muscular fibers from the aponeuroses of the external oblique muscle of the abdomen. The course of the muscle fibers was similar to that of the others, upward and medially 
and were inserted to the junction of the manubrium and the body of the sternum. The nerve supply was not determined. (We were not able to make a drawing of this case.)

Case V. Male, prisoner, 20 years old, musculus sternalis, unilateral, right. It measured $10 \mathrm{~cm}$. long and $2.5 \mathrm{~cm}$. wide. It originated from the fascia covering the lower portion of the right pectoralis major, it ran upward and medially and was inserted by two tendinous slips, the upper one to the middle of the lower part of the manubrium sterni at the level of the second rib, and the lower slip to the middle of the body of the sternum at the level of the third rib. The nerve supply was from one of the intercostals.

Case VI. Female normal foetus. Musculus sternalis, bilateral. The right muscle was $4.4 \mathrm{~cm}$. long and $0.8 \mathrm{~cm}$. wide (widest part). It originated by muscular fibers from the sixth cartilage and the costal origin of the pectoralis major. The fibers coursed upward and medially gradually tapering to a slender muscular band which was continnous with the right sternomastoid. The nerve supply was a twig from the lateral anterior thoracic. The medial border of the origin was about $0.6 \mathrm{~cm}$. from the midsternal line.

The left was $4 \mathrm{~cm}$. long and $0.95 \mathrm{~cm}$. wide (widest part). Origin by a wide and flat tendinous band from the apponeurosis of the external oblique, the rectus sheath, and costal portion of the pectoralis major. It ran upward and medially and was partly inserted by muscular fibers to the sternal portion of the pectoralis major at the level of the second interspace and partly by muscular fibers which crossed the middle line of the sternum at the level of the second rib to be inserted into the right pectoral major. The nerve supply not identified. The medial border of the origin was $1.1 \mathrm{~cm}$. from the midsternal line.

Case VII. Male normal foetus. Musculus sternalis bilateral. The right muscle was $3.4 \mathrm{~cm}$. long by $0.5 \mathrm{~cm}$. wide at widest point. Origin, by aponeurotic band from the costal portion of the pectoralis major at the level of the fifth interspace, the fibers course upward and medially and at the level of the third interspace, the muscle bifurcated, the lateral muscular fasiculus was inserted to the sternal portion of the great pectoral at the level of the third rib, and the medial band which was semitendinous was continuous with the sternomastoids above. The nerve supply was not found. The medial border of the origin was $0.9 \mathrm{~cm}$. from the midsternal line.

The left was $3.7 \mathrm{~cm}$. long and $0.9 \mathrm{~cm}$. wide (widest part). It originated by muscular fibers from the sixth rib and the adjoining costal portion of the great pectoral, the fibers course upward and medially, tapering to a semitendinous band which also become continuous with both sternomastoids. The nerve to the muscle was not found. The medial border of the origin was $0.95 \mathrm{~cm}$. from the middle line.

Case VIII. Anencephalous foetus, female. Musculus sternalis, bilateral. The right muscle was much larger than the left, it measured $4.5 \mathrm{~cm}$. long and $1.7 \mathrm{~cm}$. wide. It originated by a tendinous band partly from the aponeurosis of the external oblique and partly from the 
pars abdominalis of the right pectoralis major. The medial border of its origin was $1.2 \mathrm{~cm}$. from the middle line. The fleshy fibers ran upward and medially, making a curve convex outward and gradually tapering to be inserted by muscular fibers to the middle of the lower portion of the manubrium sterni and by deep fibers to the second costal cartilage. There was a distinct triangular interval between this muscle and the clavicular and abdominal portions of the pectoralis major, where its nerve was seen coursing to penetrate the substance of its deep surface. By reflecting laterally the upper portion of the clavicular and sternal portions of the pectoralis major, this nerve was traced over the pectoralis minor from the musculus sternalis upward and laterally to the point where it pierced the costocoracoid membrane, where it was identified as the medial anterior thoracic nerve.

The left muscle originated by a flat thin tendon not unlike ordinary fascia from the lower part of the costal portion of the left pectoralis major, it ran upward and medially, and at the level of the second rib, it was joined at its lateral side by a small muscular slip from the left pectoralis major. It divided at this level into two flat tendons, the lateral one was inserted with the right muscle to the middle of the lower portion of the manubrium sterni and the medial tendon to the middle of the upper portion of the body of the sternum. This muscle measured $2.7 \mathrm{~cm}$. long and $0.4 \mathrm{~cm}$. wide. The medial border of its origin was 0.5 $\mathrm{cm}$. from the middle line. No nerve to this muscle was observed.

Case IX. Anencephalous foetus, female. Musculus sternalis, bilateral. The right muscle was smaller than the left. It measured $2 \mathrm{~cm}$. long and $0.7 \mathrm{~cm}$. wide. Its origin was by muscular fibers from the pars abdominalis of the right pectoralis major, some of the fibers originating from its deep surface. The muscle ran upward and medially and was was inserted by fascial attachment to the sternal portion of the right pectoralis major at the level of the third rib. The medial border of its origin was $1.2 \mathrm{~cm}$. from the middle line. Its nerve supply pierced both pectoral muscles and reached the musculus sternalis at its deep surface. It was identified to be the medial anterior thoracic.

The left muscle was much larger, it measured $3.5 \mathrm{~cm}$. long and $1.1 \mathrm{~cm}$. wide. Its origin was by a flat tendinous band from the aponeurosis of the external oblique, it ran upward and medially and was inserted by two tendinous ends, the lateral to the third costal cartilage and the medial crossed the median line to the right side and was inserted in common with that of the right muscle to the middle sternal portion of the right pectoralis major at the level of the third rib. The medial border of its origin was about $1.4 \mathrm{~cm}$. from the middle line. Its nerve supply was identical with that of the right muscle.

Case $X$. Anencephalous monster, female. Musculus sternalis, bilateral. The right muscle was much larger than the left measuring $5.4 \mathrm{~cm}$. long and $1.7 \mathrm{~cm}$. at its widest part. The medial border of the origin was 1.8 $\mathrm{cm}$. from the midsternal line. It originated from rectus sheath and apponeurosis of the external oblique, the fibers ran upward and medially, and at the level of the third costal cartilage it bifurcated, the lateral 
muscular band was inserted into the sternal portion of the pectoralis major at the second interspace and the medialend tapered in a tendinous band inserted into the sternal portions of the two pectorals at about the median line. The nerve supply was by a filament from the third intercostal.

The left was very small, it measured $2.1 \mathrm{~cm}$. long and $0.3 \mathrm{~cm}$. at widest portion. Its origin was muscular from the costal portion of the great pectoral at the level of the fifth rib $1.1 \mathrm{~cm}$. from the median line of the sternum, the fibers ran upward and medially and were inserted directly to the sternal portion of the pectoral at the level of the upper border of the third rib. Nerve supply was not found.

The right muscle was larger. It measured $4.4 \mathrm{~cm}$. long and $1 \mathrm{~cm}$. wide. It was apparently made up of two parts, separated by denser fascia, one superficial and lower originated from the aponeurosis of the external oblique and the abdominal portion of the great pectoral, its fibers ran upward and medially, and at the level of the fourth costal cartilage they blended with those of the deeper part and continued upward to gain insertion by semitendinous connection to the manubrium sterni. The deeper portion originated by muscular slips from the aponeurosis of the external oblique and by tendinous origin fron the costal portion of the great pectoral under cover of the superficial part, and after pursuing a vertically upward course was inserted by muscular attachment to the anterior part of the sternoclavicular joint. The medial border of the origin of the muscle was $1.2 \mathrm{~cm}$. from the median line. Its nerve was not found.

The left was much smaller. It measured $2.2 \mathrm{~cm}$. long and $0.25 \mathrm{~cm}$. wide. Origin, by long slender tendinous slip from the sternal portion of the pectoralis major at the level of the fourth costal cartilage, the fibers ran upward and medially and were inserted directly to the upper border of the manubrium sterni near the median line. Nerve supply not found. The medial border of the origin was $0.4 \mathrm{~cm}$. from the midsternal line.

Table 1 shows the distribution of the muscle.

From the above cases we see that the attachments, relations, and sizes of the musculus sternalis are so manifold that a description of one specimen is not an adequate account for all, no two specimens being exactly alike. In this respect it is different from other muscles of the body, which, as a rule, have a constant origin, insertion, relations, and nerve supply. Its size in our cases varied from $2 \mathrm{~cm}$. to $10 \mathrm{~cm}$. long and from $0.25 \mathrm{~cm}$. to $2.5 \mathrm{~cm}$. wide. We can say, however, that in every case, the muscle was found lying over the pectoralis major at varying distances from the sternum. With regard to origin we found that the muscle 
started sometimes from the aponeurosis of the external oblique, at others from the abdominal portion of the great pectoral, rectus sheath, or from the lower costal cartilages. Again this origin varied from fascial bands to muscular or tendinous slips.

Its insertions again were varied. In some cases it was found inserted in the manubrium sterni, in others in the body of the

TABLE 1

\begin{tabular}{|c|c|c|c|c|c|c|c|c|}
\hline \multirow[b]{2}{*}{$\begin{array}{l}\text { BCHOOL } \\
\text { YEAR }\end{array}$} & \multirow{2}{*}{$\begin{array}{l}\text { NUM- } \\
\text { BER OF } \\
\text { BPECI- } \\
\text { MENB } \\
\text { EXAM- } \\
\text { INED }\end{array}$} & \multicolumn{6}{|c|}{ PRESENCE OF MCSCULUB RTERNALIB } & \multirow[b]{2}{*}{ INNERVATION } \\
\hline & & Casea & Male & Female & $\begin{array}{c}\text { Unilateral or } \\
\text { bilateral }\end{array}$ & $\begin{array}{l}\text { Num- } \\
\text { ber of } \\
\text { speci- } \\
\text { mens }\end{array}$ & $\begin{array}{c}\text { Per- } \\
\text { centage }\end{array}$ & \\
\hline
\end{tabular}

a. Musculus sternalis in adult Filipino cadavers

\begin{tabular}{|c|c|c|c|c|c|c|c|c|}
\hline $1915-16$ & 60 & I & 1 & & Unilateral & 1 & 1.66 & $\begin{array}{l}\text { Medial anterior } \\
\text { thoracic }\end{array}$ \\
\hline $1917-18$ & 38 & $\begin{array}{l}\text { II and } \\
\text { III }\end{array}$ & & 2 & Bilateral & 4 & 5.26 & $\begin{array}{l}\text { Both anterior } \\
\text { thoracic }\end{array}$ \\
\hline $1918-19$ & 14 & IV & & 1 & Bil & 2 & 7.14 & Undertermined \\
\hline $1920-21$ & 24 & $\mathrm{~V}$ & 1 & & Unilateral & 1 & 4.16 & Intercostal \\
\hline Total & 136 & 5 & 2 & 3 & & 8 & 3.67 & \\
\hline
\end{tabular}

b. Musculus sternalis in Filipino foetuses

\begin{tabular}{l|c|c|c|c|c|c|c|c}
\hline 1920 & 10 & $\begin{array}{c}\text { VI and } \\
\text { VII }\end{array}$ & 1 & 1 & Bilateral & 4 & 20 & $\begin{array}{c}\text { Lateral anterior } \\
\text { thoracic }\end{array}$ \\
\hline
\end{tabular}

c. Musculus slernalis in anencephalic Filipino foetuses

\begin{tabular}{l|l|l|l|l|l|l|l|l}
\hline 1920 & 10 & $\begin{array}{c}\text { VIII to } \\
\text { XI }\end{array}$ & 4 & Bilateral & 8 & 40 & $\begin{array}{l}\text { Medial anterior } \\
\text { thoracic and } \\
\text { third inter- } \\
\text { costal }\end{array}$ \\
\hline
\end{tabular}

sternum and upper costal cartilages, or even blending with the upper origins of the pectoralis major or the sternal origins of the sternocleido mastoids. Here also the insertion was accomplished either by muscular fasciculi or by one or more tendinous connections. The nerve supply is by no means the same in every case. In our cases, however, two nerves appeared to be the main sources of nerve supply, viz., the anterior thoracics and the intercostals. This finding is confirmed by those of others, as noted in table 2 . 
The importance of the nerve supply in considering the homology of this muscle was not apparently realized by the older writers, and it is only since Cunningham (2) called attention to this fact that more careful study has been made of this part of the subject.

\section{TABLE 2}

Nerve supply of the musculus sternalis (modifed aflcr Cunningham)

\begin{tabular}{|c|c|c|}
\hline ACTHORS & $\begin{array}{l}\text { NUMHEM OF } \\
\text { M SGCLFS SCPPLIED } \\
\text { BY ANTERIOH } \\
\text { THORACICS }\end{array}$ & $\begin{array}{c}\text { NUMBER OF } \\
\text { MUSCLES BUPPLIED } \\
\text { BY } \\
\text { INTERCOBTALS }\end{array}$ \\
\hline Shepherd. & 7 & \\
\hline Wallace........... & 1 & \\
\hline Lamont............. & 6 & \\
\hline Dwight.......... & 2 & 2 \\
\hline Cunningham............ & 17 & \\
\hline Hallett.............. & & 1 \\
\hline Bardeleben..$\ldots \ldots \ldots \ldots \ldots \ldots \ldots$ & & 2 \\
\hline 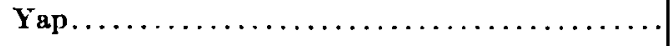 & 9 & 2 \\
\hline Total. . & 42 & 7 \\
\hline
\end{tabular}

TABLE 3

Musculus sternalis in different nationalities (modified after Ruge)

\begin{tabular}{|c|c|c|}
\hline AтTHORS & NATIONALITIES & PERCENTAGE \\
\hline Chudzinski, Le Double and Testut..... & Negro & 8.4 \\
\hline 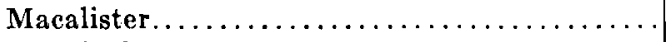 & Irish & 6.0 \\
\hline 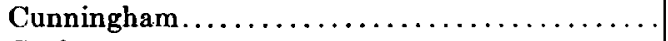 & Irish & 4.4 \\
\hline Gruber.................... & Russian & 5.26 \\
\hline Le Double........... & French & 4.65 \\
\hline Wood........ & English & 4.0 \\
\hline Turner............... & Scotts & 3.23 \\
\hline Schwalbe and Pfitzner... & Alsace-Lorraine & 3.24 \\
\hline Yap................ & Filipinos (adults) & 3.67 \\
\hline
\end{tabular}

In the beginning of this paper I called attention to the fact that the musculus sternalis was found in different nationalities. I am inserting the following table showing this occurrence and its relative proportion in different races as reported by various writers (table 3). 
The occurrence of this muscle in the two sexes is variable. In adults some authors found it more commonly in males, while others met it more frequently in females, and there are those who reported it with equal frequency in the two sexes. I found it present in adult females in the proportion of 3 to 2 , in normal foetuses 1 to 1 , and all the cases encountered in anencephalic foetuses were in females.

TABLE 4

Relative frequency of musculus sternalis in the two sexes (modified after Cunningham)

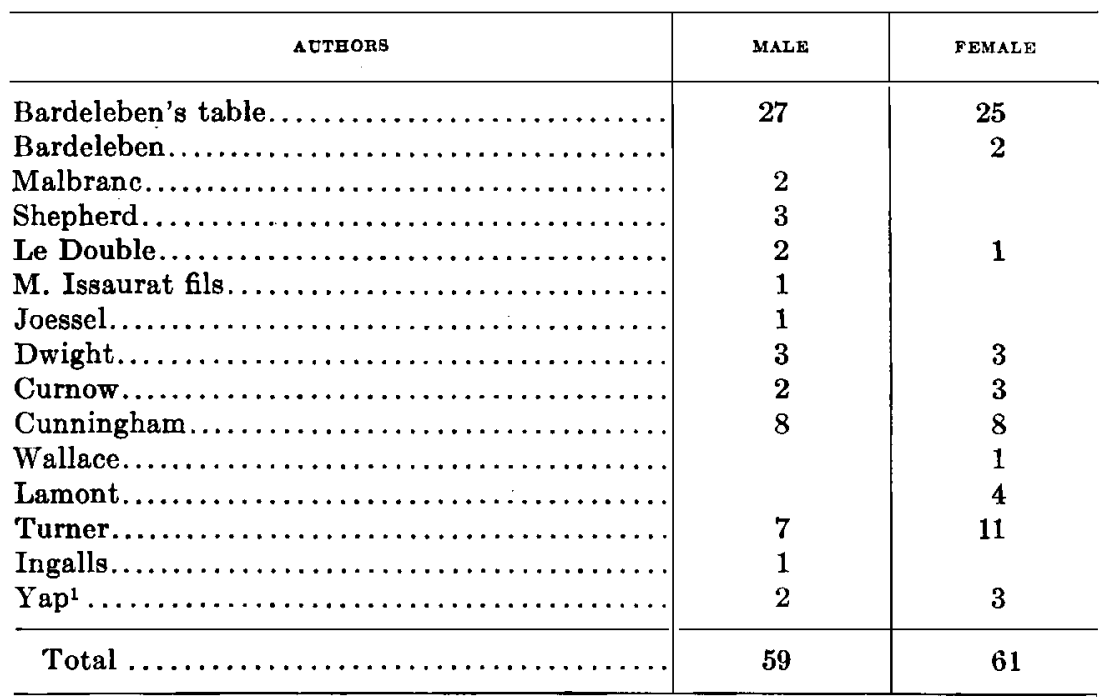

1 Only adult cases given.

Hallett (2) regards this muscle as inspiratory in function. Cunningham claims that if this were the case we should expect to find it present in greater proportion in females and his statistics show forty-nine males and forty-seven females, but he failed to include Turner's findings, on the ground that more females were encountered in the latter's dissecting-room. Without intending to argue the matter, we wish to call attention to our table 4 and to our previous statement regarding the preponderance of male cadavers in our dissecting-room. Moreover, we found the 
muscle present in five female foetuses and in only one male, and Shepherd in five out of six female anencephalous monsters.

As to its occurrence as a double muscle in the two sexes, the same uncertainty is noted. I found it bilateral in all my female cases, while in all the male cases, except the male normal foetus, it was unilateral.

TABLE 5

Relative frequency of double sternalis in the two sexes (modified after Cunningham)

\begin{tabular}{|c|c|c|}
\hline AUTHORA & MALE & FEMALE \\
\hline Bardeleben's table... & 6 & 4 \\
\hline Melbranc................. & 1 & \\
\hline Le Double................ & 1 & 1 \\
\hline Joessel............ & 1 & \\
\hline Dwight $\ldots \ldots \ldots \ldots \ldots \ldots \ldots \ldots \ldots \ldots \ldots \ldots \ldots$ & 1 & 1 \\
\hline 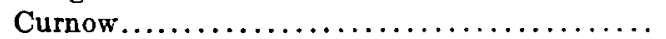 & 1 & 2 \\
\hline Cunningham $\ldots \ldots \ldots, \ldots, \ldots, \ldots, \ldots, \ldots, \ldots$ & 2 & 2 \\
\hline Ingalls $\ldots \ldots \ldots \ldots \ldots \ldots \ldots \ldots \ldots \ldots \ldots$ & 1 & \\
\hline Yap ${ }^{1} \ldots \ldots \ldots \ldots \ldots \ldots \ldots \ldots \ldots \ldots \ldots \ldots \ldots \ldots$ & & 3 \\
\hline Total... & 14 & 13 \\
\hline
\end{tabular}

Only adult cases given.

In the anencephalous foetuses it was noted in much greater proportions, varying from 16 to 88 per cent. I found it present in my series in about 40 per cent. There is as yet no definite explanation advanced to account for this frequency of occurrence. Shepherd (4) seems to believe that it points rather to its being a rudiment than a new muscle:

Windle (cited by Ruge (3) ) comes forward with the suggestion that the muscle might be found in greater proportion in lunatics, evidently basing his belief on the frequency of its presence in anencephalous monsters. He does not, however, attempt to offer any basic reason for such suggestion. We cannot at present advance any opinion on this aspect of the subject; we wish, nevertheless, to call attention to the high percentage of the musculus sternalis ( 40 per cent) in the anencephalous foetuses examined by us, and the fact that out of five adults which showed the muscle in our series, two were chronic insanes and two were 
criminals. It would seem that this point might be further looked into with a view of explaining the connection between this anomaly and insanity, if there is really such a relation.

TABLE 6

Musculus sternalis in anencephalic foetuses (modified after Ruge)

\begin{tabular}{|c|c|c|c|}
\hline AUTHORS & $\begin{array}{c}\text { NCMBER OF } \\
\text { CASES }\end{array}$ & $\begin{array}{l}\text { NUMBER OF } \\
\text { TIMES FOUND }\end{array}$ & PERCENTAGE \\
\hline Shepherd $\ldots \ldots \ldots \ldots \ldots \ldots \ldots$ & 9 & 8 & 88.0 \\
\hline Eisler........ & 7 & 4 & 57.0 \\
\hline 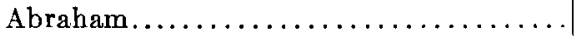 & 11 & 6 & 54.0 \\
\hline 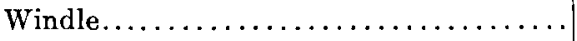 & 27 & 10 & 37.0 \\
\hline 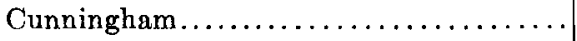 & 6 & 1 & 16.6 \\
\hline 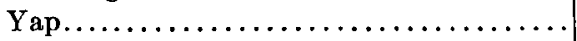 & 10 & $4^{1}$ & 40.0 \\
\hline Total. . & 70 & 33 & 47.14 \\
\hline
\end{tabular}

1 Double.

The homology of the musculus sternalis is as yet a question that remains unsettled. Anatomists who have given extensive accounts of the muscle vary in their views. Some based their conclusions chiefly from its connections, while others took into consideration its nerve supply, and there are. those who look upon it as a muscle sui generis and peculiar to man. There are at present five hypotheses of interest regarding the homology of this muscle:

1. That the muscle is a remnant of the paniculus carnosus and associated in man with the platysma myoides.

This theory is ably and extensively discussed by Professor Turner (1), whose views are shared by Hallet, Parson, Lambert (3), and a few others.

Turner seems to base his conclusions on these observations:

$a$. That in muscular subjects the platysma myoides descended over the clavicle and above the pectoralis major for a considerable distance ( 2 to 4 inches) on the anterior surface of the chest.

$b$. The fact that occasionally portions of the paniculus carnosus, besides the platysma and the palmeris longus, are found in other parts of the body. 
c. The occasional crossing of the platysma myoides in front of the sternum as observed by Teichmann, resembling in such cases the position assumed sometimes by the musculus sternalis.

$d$. That in lower animals the paniculus carnosus is well developed in the ventral surface, and extends with a marked process over the pectoralis major.

There are two points which in our mind speak against the above hypothesis:

$a$. The fact that the platysma is found in the superficial fascia, whereas the musculus sternalis is under it, so that the two muscles are in two distinct morphological planes.

$b$. And the other, as Cunningham (2) points out, is the innervation of the muscle. He correctly reasons that if the muscle were a part of the paniculus carnosus, we should expect it to be innervated by a special branch from the brachial plexus, whereas all the observations reported so far indicate that it derives its nerve supply from the anterior thoracic nerves or the intercostals.

Parson (3), in his work on rodents, claims that the musculus sternalis may be the persistence of the deeper layer of the pectoral section of the paniculus carnosus. But here again the nerve supply of the muscle speaks against this view.

2. Albinus (1) first advanced a theory which regards the musculus sternalis as an upward extension of the rectus abdominis muscle. Turner, however, claims that in all those mammals where the rectus abdominis is prolonged upward, the fibers of the prolongation were always encountered under the great pectoral muscle and in contact with the ribs, whereas the musculus sternalis in man is always found superficial to the pectoralis major.

3. Bourienne (3) is responsible for the theory which regards the musculus sternalis as a downward prolongation of the sternocleido mastoid muscle. He was later supported by Henle, Marjolin, Gegenbaur, Theile (3), and others. It is a point of common observation that the sternal origin of the sternomastoid is in common with the insertion of the musculus sternalis. I found this to be the case in five out of eleven cases and Turner in thirteen out of twenty one. Cunningham (2), in discussing this view, says that if the musculus sternalis were a part of the 
sternomastoid, we should expect it to be innervated by some branch of the spinal accessory or the cervical plexus, which occurrence, however, has never been reported. Ruge (3) claims that in no animals the sternomastoid extends to the abdomen or to the aponeurosis of the external oblique, and that, furthermore, the innervation of the musculus sternalis is against the above theory.

As modifications of the above two hypotheses we also find the following views:

$a$. Testut with Anthony (3) believes that the upper part of the musculus sternalis belongs to the sternomastoid, while its lower portion is a part of the external oblique muscle. This contention is based upon the claim that these two muscles (sternomastoid and external oblique) are in the same morphological plane and "that the musculus sternalis is the remnant in man of the old connection which formerly existed between the two, a connection which exists in serpents." Cunningham (2), however, contends that such a connection becomes the pectoralis major in the thrusting out of limbs. Besides, we must remember that serpents are not philogenetically related to mammals.

$b$. Bardeleben (2) claimed that the musculus sternalis when receiving its nerve supply from the intercostals must be considered as belonging to the sternomastoid, and when innervated by the anterior thoracies to the pectoral group.

Cunningham (2) takes exception to this view, on the ground that in the majority of cases which he recorded as supplied by the anterior thoracic nerves, the muscles were directly continuous with the sternomastoid. This fact was confirmed by us in five of our cases; furthermore, there are cases in which musculus sternalis, though innervated by the intercostals, were not continuous with the sternomastoid.

4. That the musculus sternalis is a muscle sui generis and peculiar to man, without a representative in lower animals. This view was advanced by Professor Halbertsma (1).

5. The musculus sternalis belongs to the pectoral group of muscles. This last view was first advanced by Bardeleben, who claimed that a certain proportion of the muscles could be considered as portions of the pectoralis major. 
Abraham (2) applied this view more extensively. He considered all sternal muscles without exception as aberrant portions of the great pectoral.

Cunningham and Shepherd, on the strength of the innervation of the muscle by the anterior thoracic nerves, strongly support the above view. Their finding has been confirmed by other observers and we have also verified it in six cases.

The above authors further contend in favor of this theory the fact that some fibers of the musculus sternalis in some instances appeared directly continuous with the pectoralis major. Such instance was encountered several times in our series.

Another point which might also be mentioned in support of this hypothesis is the presence of a gap or deficiency in the fibers of the great pectoral at the lateral side of the musculus sternalis.

Such occurrence was reported by Shepherd in four of his cases and we have met it once in our study. We agree with Cunningham when he said, "it is reasonable to suppose that the gap is caused by the abstraction of this portion of the muscle to form the sternalis and there are many cases figured which would lead one to suspect that the rotation of fibres has taken place in an upward and inward direction."

The above explanation would surely account for those cases where the lower end of the muscle lies under cover of the great pectoral. Ruge, after an extensive discussion of the above different theories is inclined to agree with Cunningham that the sternalis is probably a portion of the pectoralis major.

Our present study inclines us to agree with the preceding explanation of the homology of the muscle. We have found the muscle supplied by the anterior thoracic nerves in six out of eight cases; we met it in close relationship with the pectoralis major and in several cases there was a direct muscular connection between the two, either in the points of origin or at the ends of insertion, and finally we also found one case where a decided gap was seen in the pectoralis major just lateral to the sternalis.

Furthermore, we quote the following from Lewis (6) on the formation of the pectoralis major: "The pectoralis major early splits into a series of overlapping bundles, and during the migra- 
tion of the muscle the superficial fibres of each bundle move farther caudally than the deeper ones, giving the overlapping condition found in the adult."

It will not be too far fetched to suppose that sometimes some of the superficial fibers split from the pectoral muscle mass and fail to migrate caudally with the rest, forming in that manner the narrow sternalis muscle.

We wish to express our indebtedness to Dr. Otto Schobl, of the Bureau of Science, for kindly helping us in the translation of some of the literature.

\section{LITERATURE CITED}

1 Torner, W. 1867 Jour. of Anat. and Phys., vol. 1, p. 246.

2 Cunningham, D. J. 1884 Jour. of Anat. and Phys., vol. 18, p. 208. 1887-8 ibid, vol. 22 , p. 391.

3 Ruge, George. 1905 Morphol. Jahrbuch, Bd. 33, S. 348.

4 Shepherd, F. J. 1885 Jour. of Anat. and Phys., vol. 19, p. 311.

5 Ingalls, N. W. 1913 Anat. Rec., vol. 7, p. 203.

6 Lewis, W. H. 1910 Keibel and Mall Embryology, vol. 1, p. 488. 


\section{FLATES}




\section{PLATE 1}

\section{EXPLANATION OF FIGURES}

Drawings by Vicente Santos

Case I Male, 36 years. Musculus sternalis unilateral, left. Origin: Pars abdominalis of left pectoral major at level of sixth rib. Insertion: Second costal cartilage blending with pectoralis major and sternomastoid. Nerve supply: Medial anterior thoracic.

Case II Female, 85 years. Musculus sternalis bilateral. Origin: (Both) pectorali major at level of fourth rib. Insertion: Anterior surface of sternoclavicular joint blending with corresponding sternomastoid. Nerve supply: Anterior thoracic.

Case III Female, 89 years. Musculus sternalis bilateral. Left muscle, shorter and smaller. Origin: Left rectus sheath and sixth rib. Insertion: Manubrium sterni at level of second rib. A tendinous slip from this unites with the tendon of the right muscle. Nerve supply: Anterior thoracic. Right muscle: Origin: Right rectus sheath and sixth rib. Insertion: In common with the sternal origins of the two sternomastoid. Nerve supply: Anterior thoracic.

Case V Male, 20 years. Musculus sternalis, unilateral, right. Origin: Fascia covering lower portion of pectoralis major. Insertion: Upper tendon to manubrium sterni; lower tendon to body of sternum at level of third rib. Nerve supply: Intercostals. 


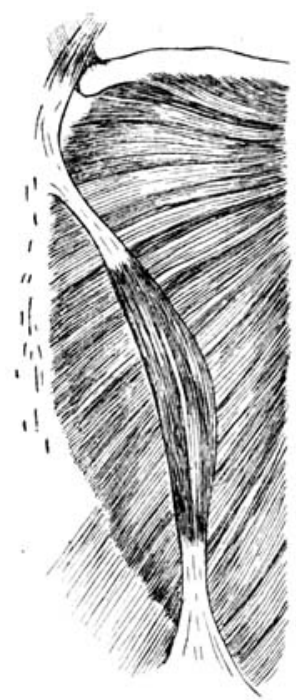

Case I

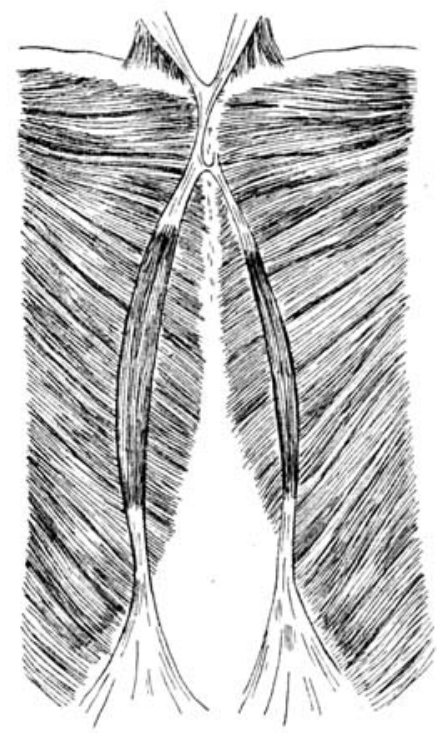

Case 111

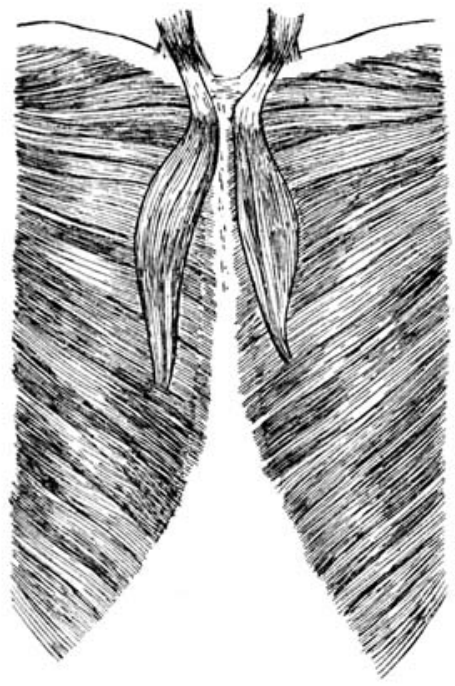

Case II

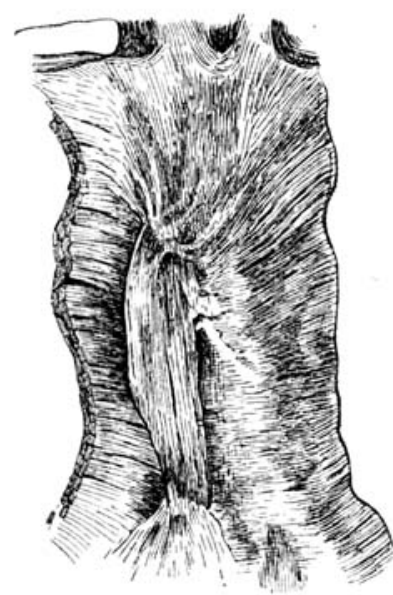

Case V 
PLATE 2

EXPLANATION OF FIGURES

Drawings by Vicente Santos

Case VI Normal foetus, female. Musculus sternalis, bilateral. Right muscle: Origin: Sixth costal cartilage and costal origin of pectoralis major. Insertion: Continuous with the right sternomastoid. Nerve supply: Lateral anterior thoracie nerve. Left muscle: Origin: Aponeurosis of external oblique, rectus sheath, and costal portion of pectoralis major. Insertion: Sternal portion of pectoralis major at level of second interspace and to the right pectoral major at level of second rib. Nerve supply: Not identified.

Case VII Normal foetus, male. Musculus sternalis, bilateral. Right muscle: Origin: Costal portion of pectoralis major at level of fifth interspace. Insertion: Sternal portion of great pectoral at level of third rib and to the sternomastoids. Nerve, supply: Not found. Left muscle: Origin: Sixth rib and adjoining portion of the pectoralis major. Insertion: To both mastoid muscles. Nerve supply: Not found.

Case VIII Anencephalous monster, female. Musculus sternalis, bilateral. Right muscle: Origin, aponeurosis of external oblique muscle and pars abdominalis of the great pectoral. Insertion: Lower portion of manubrium and to second cartilage. Nerve supply: Medial anterior thoracic. Left muscle: Origin: Costal portion of pectoralis major and by a small slip from the middle part of the muscle. Insertion: Lower portion of manubrium and upper portion of the body of the sternum. Nerve supply: Not founa'.

Case IX Anencephalous monster, female. Musculus sternalis, bilateral. Right muscle: Origin: Pars abdominalis of great pectoral; Insertion: Sternal portion of right pectoral major at level of third rib. Nerve supply: Medial anterior thoracic. Left muscle: Origin: Aponeurosis of external oblique. Insertion: Third costal cartilage and in common with the right musculus sternalis into the sternal part of the great pectoral muscle at level of third rib. Nerve supply: Medial anterior thoracic.

Case X Anencephalous monster, female. Musculus sternalis, bilateral. Right muscle: Origin: Rectus sheath and aponeuros's of external oblique. Insertion: Sternal portion of great pectoral at level of second interspace and into sternal portions of the two pectorals at median line. Nerve supply: Third intercostal. Left muscle: Origin: Costal portion of great pectoral at level of fifth rib. Insertion: Sternal portion of great pectoral at level of upper border of third rib. Nerve supply: Not found.

Case XI Anencephalous monster, female. Musculus sternalis, bilateral. Right muscle: Origin: Aponeurosis of external oblique and abdominal portion of great pectoral. Insertion: Manubrium sterni and anterior part of the sternoclavicular joint. Nerve supply: Not found. Left muscle: Origin: Sternal portion of great pectoral at level of fourth costal cartilage. Insertion: Upper border of the manubrium sterni. Nerve supply: Not found. 

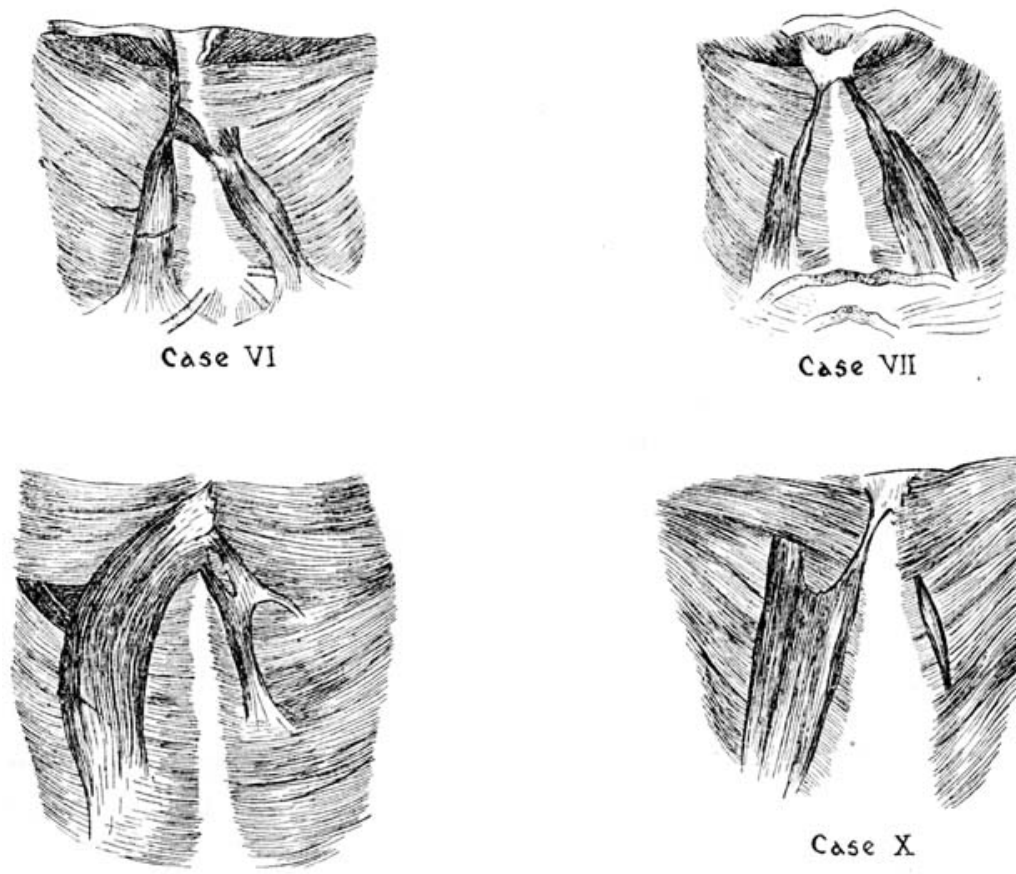

Case. VIII
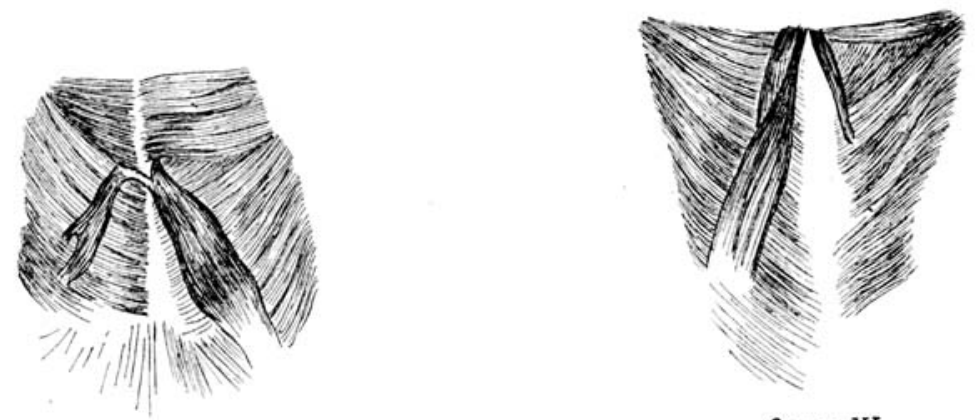

Case IX

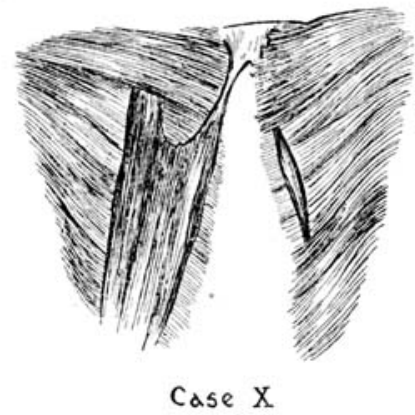

Case XI 